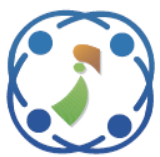

\title{
Eye State Recognition Using Multiple Methods for Applied to Control Smart Wheelchair
}

\author{
Gusti Pangestu $^{1} \quad$ Fitri Utaminingrum $^{1 *} \quad$ Fitra A. Bachtiar $^{2}$ \\ ${ }^{I}$ Computer Vision Research Group, Faculty of Computer Science, Universitas Brawijaya, Indonesia \\ ${ }^{2}$ Intelligence System Research Group, Faculty of Computer Science, Universitas Brawijaya, Indonesia \\ * Corresponding author's Email: f3_ningrum@ub.ac.id
}

\begin{abstract}
People with multi-disability order need more handling than normal people. Smart wheelchair also developed with conventional mechanism that has more improvement in any aspect such as automatic system until control system. We develop a way for controlling smart wheelchair with movement of eyelid. In other ways, our system have capability to recognize state of the eye whether the eyes in opened or closed state. Opened and closed state in the eye can made a benchmark to control a wheelchair. In our research, we develop a system to recognize whether eye in the opened or closed state by using Multiple Method consisting of Haar cascade to detect eye location, Vertical Image Projection (VIP) to extract the feature and Learning Vector Quantization (LVQ) Neural Networks to recognize state of the eye. Our method produce an accuracy until $90.32 \%$ to recognize eye state. This approach can be used as an alternate way to control movement such go forward or stop by using their eyelid movement in smart wheelchair for disabled people.
\end{abstract}

Keywords: Neural network, Image processing, Image recognition, Face detection, Eye detection, Eye recognition.

\section{Introduction}

According to data provided by BPS Indonesia in 2010 there were 9.046 million peoples with disabilities in Indonesia [1], the figure is relatively high when compared with the overall number of Indonesian population of around 237 million or nearly $5 \%$ of Indonesia's population with disabilities. The number in 2010 continues to increase over time, recorded in 2017 according to Sakernas there are 21,930,529 people with disabilities in Indonesia, the number is very much and will continue to grow.

The number of disabilities people give attention to develop many invention such as manual wheelchair until electric wheelchair [2]. One of the new trends in technology is using sensors for operating a wheelchairs, such as voice sensor and muscle sensor $[3,4]$.

So far people are more likely to use the old way. In this case, manual wheelchair was chosen by disability people. By using the manual wheelchair, they can operate this vehicles with their hand. But the question arise for people who had multidisabilities like hand and foot deformity. People with hand and foot deformity can rely to the nurses or their companion. But, the next question arise when they had no companion anymore who can help them control their manual wheelchair.

Recently, some research show that voice can be used as controlling navigation for electric wheelchair [5]. But disadvantage for using voice sensor is very sensitive with noise. Hence, the condition and environment should be in quiet condition.

Research on reference [6] also use a sensor called Electromyography Sensor. It used for detecting arm muscle signal by put some electrode on user-patient arm. Electromyography work by sensing 4 signal which came from the arm user. But, it is difficult when the patient or user can't operate their arm. Even more the worst case when the disabilities user have no arm anymore. Research by 


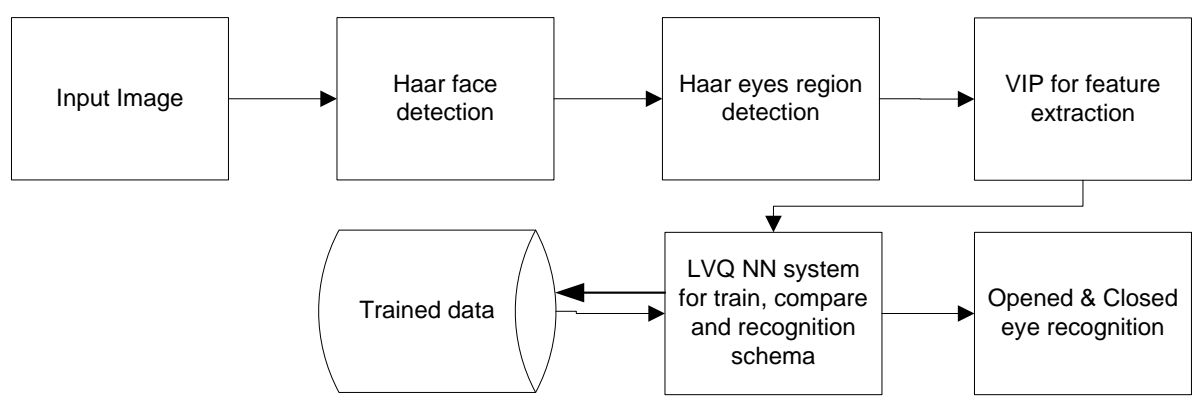

Figure. 1 State diagram

Utaminingrum et al. [7] also develop an automatic smart wheelchair that can run automatically by detecting obstacles and tracking people in front of it. But their research did not accommodate control freely for disability user.

In research [8], they show how to use the eyes as a wheelchair control, but the problem arises when eyes must continue to look up for run the wheelchair forward. User can not seeing the reality in front of them clearly, they would not actually seeing where they are going.

From this various problem, we propose a way or method for controlling the smart wheelchair by using eye, especially for moving forward and backward. The wheelchair will move to forward or stop when eye closing for several seconds, and also backward too (discussed in section 3 ).

This paper explore the state recognize method to find whether eye in open or closed state in still image. This work are important for developing a new method for controlling wheelchair especially for people with multi-disability order, for example they have no hand and foot that cannot be used for controlling a wheelchair. This research also can be combined with other research about controlling direction movement with eyeball tracker like [9] and [10] to get the best performance combination. In this work, eyelid or eye state position can be a basic command to the console for control the wheelchair to move forward, backward and stop by using time duration of eye closeness. By using our proposed method, time computation for detect eye state can be shortened and used for real-time.

Our proposed method, Haar Cascade method and Learning Vector Quantization (LVQ) neural network (HLVQ) has developed by combining Haar cascade for located the eye region in face and LVQ for recognizing the open state and closed state of the eye. Using Vertical Image projection (VIP) for extracting the feature of eye and LVQ Neural Network for recognizing the open state and closed state of the eyes using the result of VIP relief the computation process.

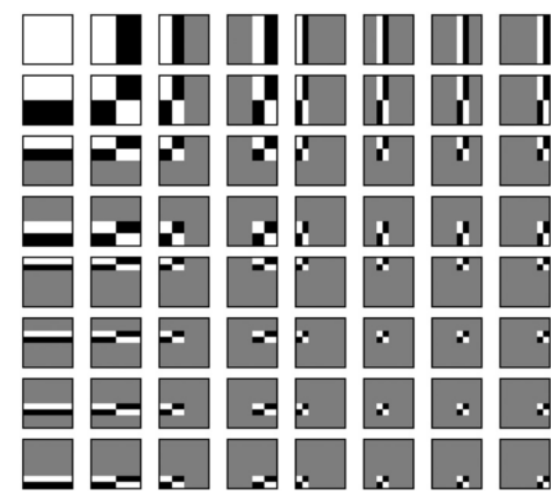

Figure. 2 Haar features

The organization of this paper represent as follows: section 2.1 are describing about Haar Cascade Method [11] for detecting and localizing face and eye region. The blink recognizing schema was described on the section 2.2. Result and analysis of research described on section 3. Conclusion and finalizing are described on section 4.

\section{Proposed method}

In this paper, we proposed Multi-method by using Haar cascade for locating eyes area and LVQ Neural Network for recognizing closed or opened eyes. By using Neural Network, we must trained the system first by using image data as shown in Fig. 1. Image data training are JPEG extension and contain open eyes images and closed eyes images. We choose many various eyes type and face type for data training like oriental face with normal eyes until Asian face with slit eyes. Data include open state eyes and closed state eyes in every subject peoples. There are two steps for recognizing eyes state, first is locating eyes and second is recognize the eyes state position.

\subsection{Detection algorithm}

The algorithm was used for locating eyes area in the image or video. First, the algorithm are locating 


\begin{tabular}{|l|l|l|}
\hline 1 & 2 & 3 \\
\hline 4 & 5 & 6 \\
\hline 7 & 8 & 9 \\
\hline
\end{tabular}

\begin{tabular}{|c|c|c|}
\hline 1 & 3 & 6 \\
\hline 5 & 12 & 21 \\
\hline 12 & 27 & 45 \\
\hline
\end{tabular}

Figure. 3 Integral image generation, the right side are the result of integral image process

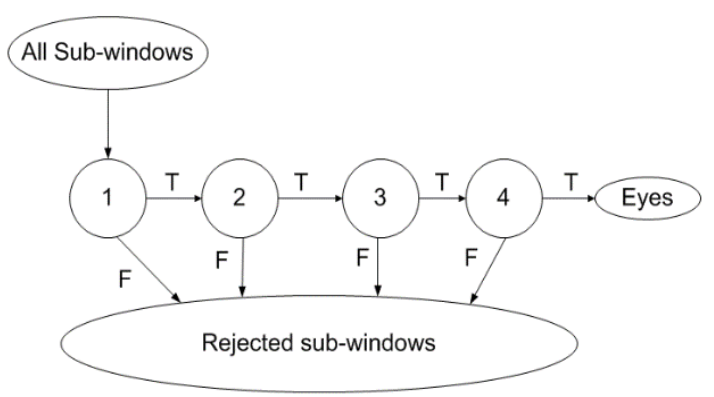

Figure. 4 Cascading mechanism

face area in the image. After face area was located, the algorithm begin to locate eyes area in the square detected before. The problem is there are two eyes in one face, so we limit the operating process for scanning with just one scan for getting only one eyes area.

\subsubsection{Haar Feature}

Haar Feature was using some several techniques of Haar Wavelet transform and Integral Image for detecting spot area in the image. Haar Feature using some feature that are composed by two or more rectangle given in Fig 2. There are many research using this method for detecting an object like people until animal [12].

These features are used in every image candidate to find a human face area. When one of these feature has found in the current stage, the algorithm allows the image candidate to pass to the next level of stage for detecting with other features again. Generally, face candidate is a rectangular section of the original image, called a sub-window. So the algorithm scans the entire image until they found a sub-window that representing a face area in the image.

\subsubsection{Integral image}

Integral image was used by Haar for accelerating the process of computation. Integral image are the second steps on the Viola-Jones algorithm. Integral image has mechanism for changes the pixel value by combining the value on the upside and left side. Integral image mechanism was described on Fig. 3. Calculating process of integral image are iterative, start from upper left end until under right end. In Fig. 3 shown value 12 in right side (middle) was counted by summing $1+2+4+5$ in left side image.

\subsubsection{Adaptive boosting}

Adaptive boosting are implemented by combining itself with Haar Features for creating the new strong learner by combining some weak learner. In general, boosting algorithm add some weak learner to the one strong learner, and changes its weight continuously. If the classification are failed, boosting will add some weight to the data. If classification successful, boosting will decreasing the weight of the data. So, in the next iteration process boosting algorithm will be focused on the data that have a big weight from unsuccessful process before.

For example we have the training sample set are $\left\{\left(s_{1}, o_{1}\right),\left(s_{2}, o_{2}\right) \ldots .\left(s_{n}, o_{n}\right)\right\}$ where $s_{1}$ are corresponding input feature and $o_{1}$ represent the output of the sample set. $o_{1}=\{0,1\}$; where "1" represent a positive sample or the target region and 0 mean negative sample which is not the target sample. The AdaBoost is computed as :

$$
h j(x)=\left\{\begin{array}{c}
1 \text { if } h j(x)<p \theta \\
0=\text { other condition }
\end{array}\right.
$$

denote $h j(x)$ are contain " 1 " when $h j(x)$ lower than $p \theta$, contain " 0 " when $h j(x)$ are have another condition.

Fig. 4 explain the cascading process. Candidate must pass all stages $(1,2,3,4 . . n)$ in the cascade to be concluded as face. If image candidate fail to pass the cascade, they will be stored in the rejected sub window. In Fig. 4, T is True and F is False.

\subsubsection{Cascade}

Viola and Jones Algorithm eliminates face candidate quickly by using cascade of stages with increases level of difficulty in every stages. The schemas are face candidate must pass all the stage for proofing there is detected face in the image. The face candidate exit the cascade if they pass all the stages or failed in any stages. The process are shown in Fig. 4.

In this research, combined algorithm called Haar Cascade Algorithm was used for detecting face area in the image. After face area was detected, the next step is detecting eye region in the square face that detected before. Image sample are given in the Fig. 5 .

There are two eyes region in the result of Haar 


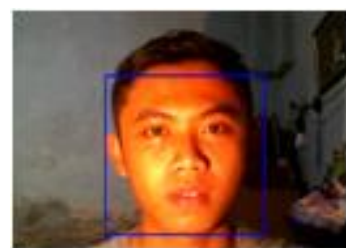

(a)

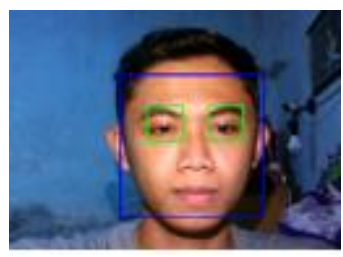

(b)
Figure. 5 Face \& eyes detection scheme: (a) face detection result and (b) eyes detection

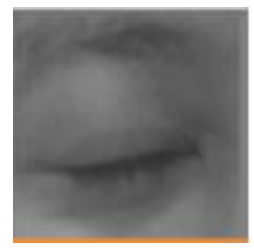

(a)

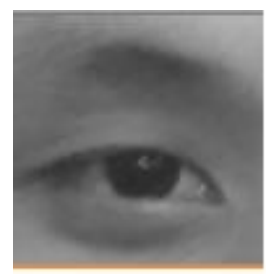

(c)

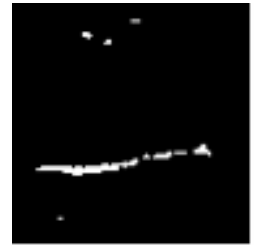

(b)

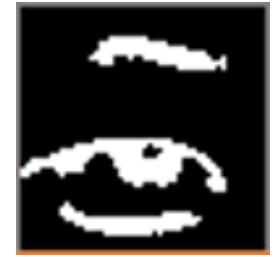

(d)
Figure. 6 Image binarization process: (a) and (c) are grayscale image, (b) and (d) are binary image

Cascade process. So, the next step is eliminate one of the two eyes square by limit the iteration process of Haar Cascade. After we get the eye region, we do the preprocessing method for get the feature of the eye image. Preprocessing method are using a binary image for transforming the RGB image to the 0 and 1 value of image or called Binary Image (represent at the Fig. 6). The biner process are given in the Eq. (2) as follows:

$$
b(i)=\left\{\begin{array}{l}
0, i \geq a \\
1, i<a
\end{array}\right.
$$

Denote $b(i)$ are the pixel result, $i$ is the pixel value and $a$ is the threshold that we are used, the value of $a$ is 60. If value of the pixel are more than $a$, change the value to the zero. If value of the pixel less than $a$, change the pixel value to the one. Remember, before we converting RGB image to the binary, we must convert the image to the grayscale first. The grayscale process was given in the Eq. (3).

$$
I=0,2989 R+0,5870 G+0,1141 B
$$

$I$ is the value result, $\mathrm{R}$ is red value, $\mathrm{G}$ is green Value and $B$ is blue value in the every pixel on the eye image.

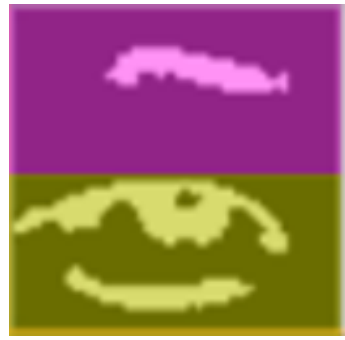

(a)

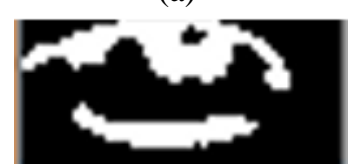

(b)

Figure. 7 Cropping eye area only: (a) image before cropping operations and (b) new image after cropping

Eyes region that detected by Haar Cascade in the previous step are cropped to the square with the same size of rows and column. In this research we use the $100 \times 100$ pixel in the every eye image detected for cropping size.

Referring to the result of binary process, we have an area that contain the eyebrows. In the image square, we see that eyebrows region are in the top of the image, and eye region are above. In the previous step, we have $100 \times 100$ pixel of the eye, so we divide the image into 2 region, the top side and the bottom side.

Bottom side of the image are the region that we will use for next process because that area are containing eye image. In this research we only need an eye image in the top side, so we will remove the top side by deleting that area. After we delete the top side, we have a new eye image that only contain eye region without interrupted by eyebrows. Process of cropping the image are shown in Fig. 7.

Fig. 7 (a) show that image are divided into 2 side, top for violet and bottom for yellow. Yellow area is the image region that we will use for detecting state. We delete the violet area by cropping the image start from half until down corner, the result was given in Fig. 7(b). After image cropping process, the result was a new eye image that only contain eye region with size fixed at $100 \times 50$ pixel. That's image will be processed later in the HLVQ method for detecting closed or opened state.

\subsection{HLVQ method for detecting closed eye}

After system can detect the eye region in face, the next step is recognizing closeness eye by use the LVQ Neural Network. By using LVQ Neural Network, we need to train the system first with the opened and closed eye image. After training process, 


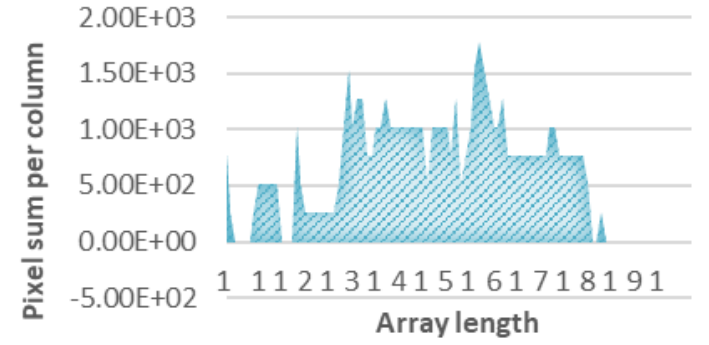

(a)

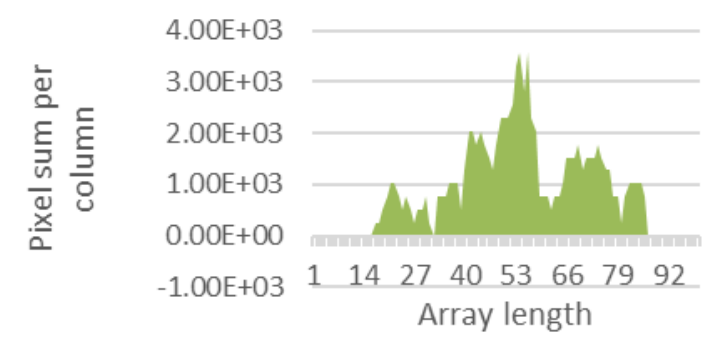

(b)

Figure. 8 Graphic result of vertical projection closed and open eye: (a) closed eye and (b) open eye

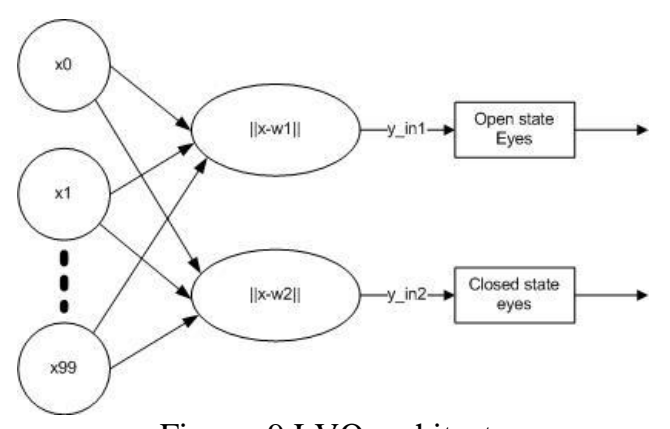

Figure. 9 LVQ architecture

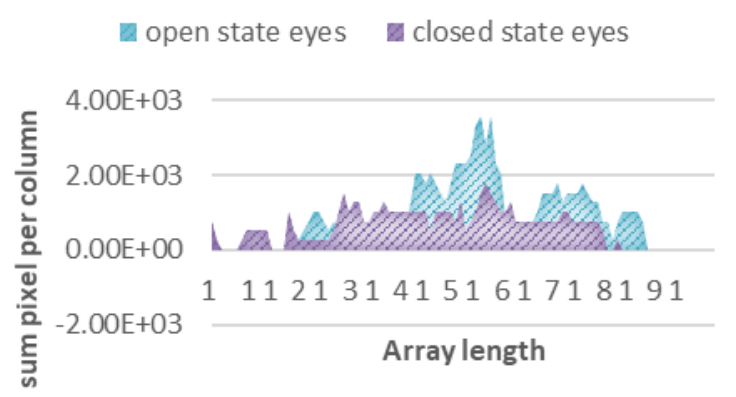

Figure. 10 The difference between open eye state and closed eye state vector data

the system will have a capability for knowing and recognizing the state of the eye whether in closed state or in opened state.

\subsubsection{Vertical projection}

Vertical projection is a shape dimension of image that calculate from image coordinate [13]. Vertical projection was describe in Eq. (4).

$$
P_{v e r}(k)=\sum_{j=1}^{M} I\left(b_{k}, k\right)
$$

Denotes $\mathrm{M}$ is the height of image, $\mathrm{N}$ is the wide of image and $\mathrm{P}$ is the sum of pixel in column $\mathrm{k}$. The size of the image is 100 x 50 px like described before. With length of the column is 50 and length of the rows is 100 , so we get the length of the vector result of Vertical Projection is 100 shown in Fig. 8.

Fig. 8 show that open state eyes (Fig.8 (a)) had more high values than close state (Fig. 8(b)). That mean we can cluster these data by using the vector value. There are many algorithm based on vector that we can implement for this case. In this research we used LVQ Algorithm for cluster and recognize the data.

\subsubsection{Learning vector quantization}

LVQ neural network is the supervised pattern recognition algorithm that do the learning first [14]. In this research LVQ was used for recognizing state of the eye whether in close state or in the opened state. Output of the LVQ training process is the vector reference use for recognizing closed state or open state in the eye image.

LVQ is the Artificial Neural Network with feedforward layer consist of input layer, competitive layer and output layer. By using LVQ, system capable to recognizes the eye state by using the vector (Fig.8) LVQ architecture showed in Fig. 9.

In this research LVQ was used for classified data training into two different class consist of opened eye and closed eye. These class classified by the similar value of the data with vector class that create before. Euclidean Distance was used for calculating the similarity between input value and class value, the Euclidean Distance process are described in Eq. 5 as follows:

$$
j\left(v_{1}, v_{2}\right)=\sqrt{\sum_{k=1}^{N}\left(v_{1}(k)-v_{2}(k)\right)^{2}}
$$

Result of Euclidean distance are used for update the vector weight:

$$
\begin{aligned}
& c_{1}=j\left(v, w_{1}\right) \\
& c_{2}=j\left(v, w_{2}\right) \\
& r=\left\{\begin{array}{l}
1, \text { if } c_{1} \leq c_{2} \\
0, \text { if } c_{2}<c_{1}
\end{array}\right.
\end{aligned}
$$




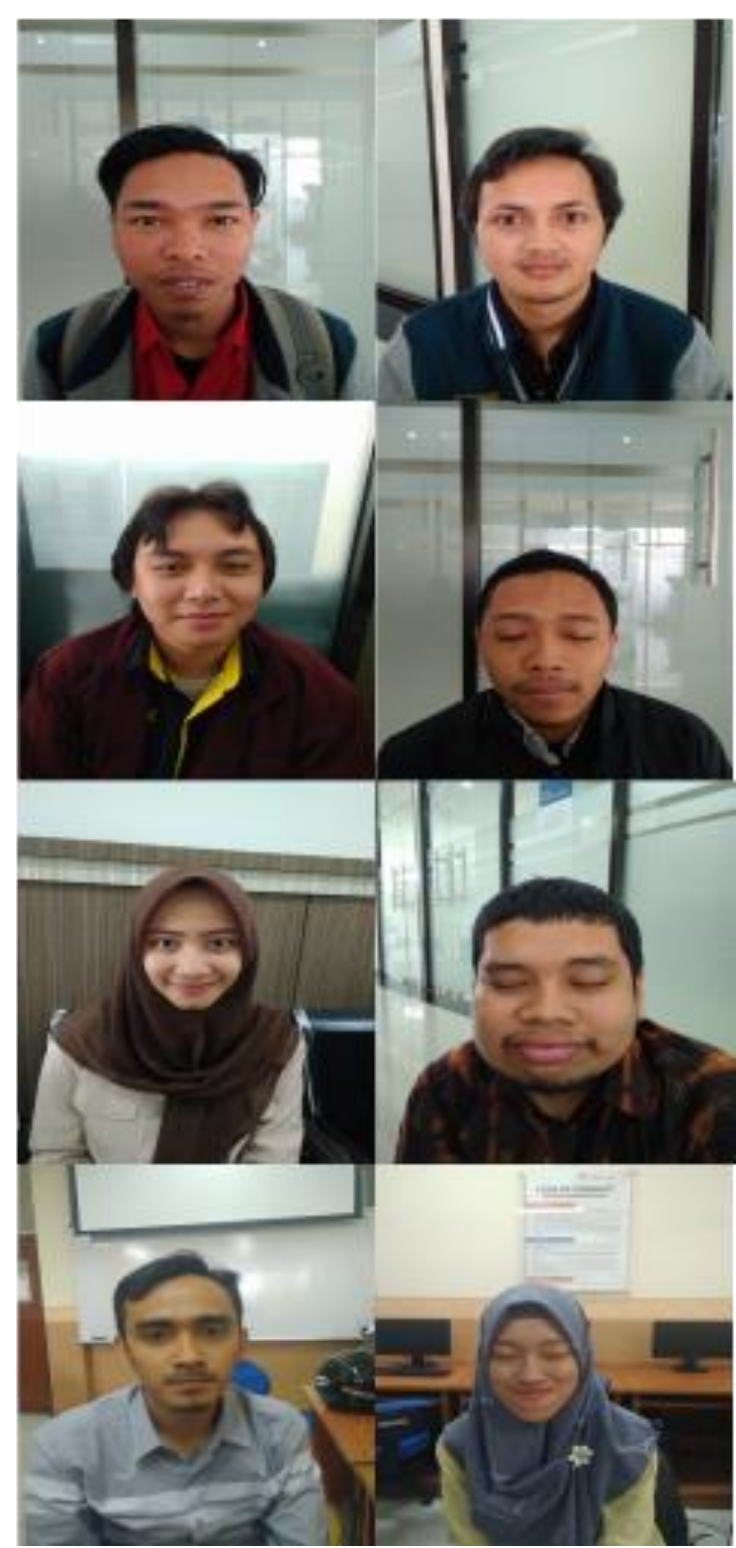

Figure. 11 Dataset samples

$w_{\text {new }}=\left\{\begin{array}{l}w_{\text {old }}+a\left(x-w_{\text {old }}\right), r=T \\ w_{\text {old }}-a\left(x-w_{\text {old }}\right), r \neq T\end{array}\right.$

denote $j\left(v_{1}, v_{2}\right)$ represent a result of Euclidean Distance, $\left(v_{1}(k)\right)$ is the vector value of input, $\left(v_{2}(k)\right)$ is weight value of old vector class, $\mathrm{T}$ is target and $\mathrm{C}$ is the result of comparison similarity between input and the two class, $r$ is 1 if $c$ more similar with $w_{1}$ and contain 0 if similar with $w_{2} .1$ and 0 represent the 2 class of vector, 1 for open eyes state class and 0 for closed eye state. If $T$ and $r$ are equal, LVQ will use the first one. But if $\mathrm{T}$ are not equal with $r$, LVQ will use the second equation.

The LVQ training process output are the database reference that consist two different classes of opened eye class and closed eye class. The output data was used for reference in the comparing process that shown on Fig. 11.

\section{Dataset}

This research focus on the accuracy for

\begin{tabular}{|l|l|l|l|l|}
\hline \multirow{2}{*}{ No } & \multicolumn{3}{|l|}{ Data testing } \\
\cline { 2 - 5 } & $\begin{array}{l}\text { Data } \\
\text { variation }\end{array}$ & Failed & $\begin{array}{l}\text { Data } \\
\text { total }\end{array}$ & Accuracy \\
\hline 1 & $\begin{array}{l}\text { Opened } \\
\text { Eyes }\end{array}$ & 2 & 31 & $93.5 \%$ \\
\hline 2 & $\begin{array}{l}\text { Closed } \\
\text { Eyes }\end{array}$ & 4 & 31 & $87 \%$ \\
\hline \multicolumn{3}{|l|}{ Total Average of Accuracy } & $90.32 \%$ \\
\hline
\end{tabular}

recognize closeness eye and time computation process on the image. From the testing, we have the result from testing 62 data including 31 data for open state eyes and 31 data for closed state eyes.

Our dataset also had multiple condition which taken in different place and different time, also have different light condition and light position. Our sample of dataset also shown in Fig. 11.

In Fig 11. There are some samples that show the contain of our dataset, every data are taken by using 13 Megapixel camera with various image background and face type.

\section{Result \& analyse}

Our research used the combined methods of Haar cascade and LVQ neural network (HLVQ) for recognize eye closeness state. We use the JPEG file data for training and testing the system. JPEG file was capturing by a camera in every respondents, we choose variation of respondents like white skin until black skin and big eyes until slit eyes. The variation of data are important for training the LVQ because more variation learned have more impact to the result. Image sample of recognition result was given in Fig. 12. Fig 12 (a), (b), (c) and (d) are the implement of correct recognition opened and closed state of the eye. Fig. 12 (e) and (f) are the sample of wrong or failed recognition opened and closed state in the eye.

There are many factors that give impact for state recognition. One of the reason are system can't detect eye location correctly. Fig. 12 (f) show that eye location detection was failed by Haar cascade method. System automatically process the input image (in this case, input image is part of the mouth (Fig. 12 (f)) to the recognition process. So the system has wrong input image and produce a wrong recognition too.

Our multiple method can produce $93.5 \%$ accuracy for recognizing open state eye and $87 \%$ for recognizing closed state eye. From these two result, 

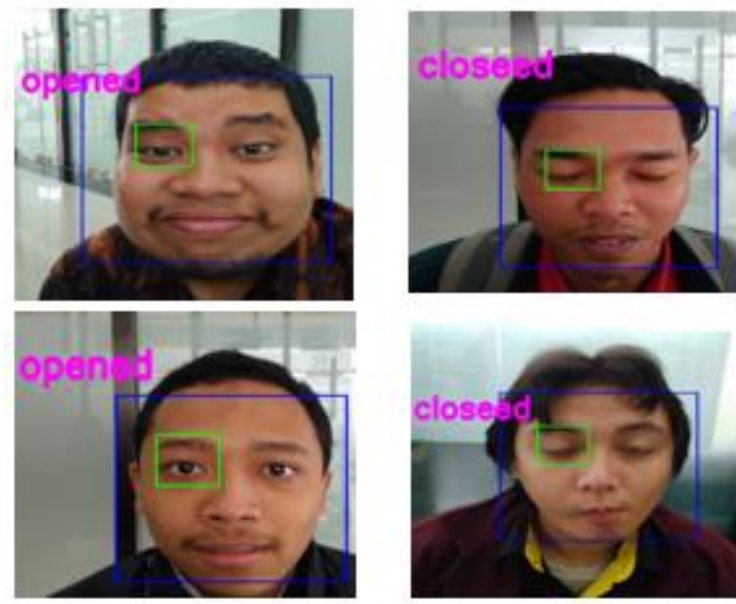

(a)
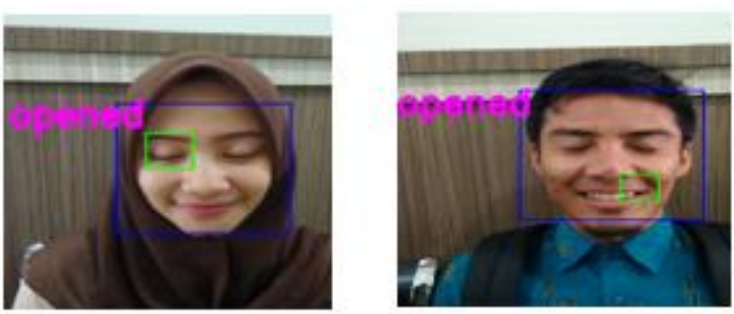

(b)

Figure. 12 Recognizing result: (a) samples of correct recognizing result and (b) samples of wrong recognizing result

we produce an average accuracy $90.32 \%$ for recognizing eye state to be used for controlling smart wheelchair by using a console system. By utilizing the results of this study, then this method can be applied to a smart wheelchair with a camera that leads to the face for recognition of eyelid movements. By using video and a timer of the system it can be determined some conditions that can be used as a reference in the movement of a wheelchair.

Our method accuracy was calculated from correct recognition divided by sum of data. As a mentioned before our research use primer data for dataset. We also survey and collect image data from people who had agreed earlier to become a part of our research. Our dataset also had multiple condition which taken in different place and different time, also have different light condition and light position.

Referring to Table 1, we can get the sum of accuracy is $90.32 \%$ with the failed recognize are 6 images consist of 2 from opened eyes data and 4 from closed eyes. Besides testing, we also calculate time process for recognizing closed eye and opened eye from still image.

By combining Haar Cascade (HC) and LVQ neural network, we produce a new way called HLVQ method. HLVQ are better than Haar
Table 1. Testing result using HLVQ proposed method

\begin{tabular}{|l|l|l|c|c|}
\hline \multirow{2}{*}{ No } & \multicolumn{4}{|c|}{ Data testing } \\
\cline { 2 - 5 } & $\begin{array}{c}\text { Data } \\
\text { variation }\end{array}$ & Failed & $\begin{array}{c}\text { Data } \\
\text { total }\end{array}$ & Accuracy \\
\hline 1 & $\begin{array}{l}\text { Opened } \\
\text { Eyes }\end{array}$ & 2 & 31 & $93.5 \%$ \\
\hline 2 & $\begin{array}{l}\text { Closed } \\
\text { Eyes }\end{array}$ & 4 & 31 & $87 \%$ \\
\hline \multicolumn{4}{|c|}{ Total Average of Accuracy } & $90.32 \%$ \\
\hline
\end{tabular}

Table 2. Comparison between our method and with only using Haar Cascade

\begin{tabular}{|l|l|l|l|}
\hline No & \multicolumn{1}{|c|}{ Function } & \multicolumn{1}{c|}{$\begin{array}{c}\text { Haar } \\
\text { Cascade }\end{array}$} & \multicolumn{1}{|c|}{ HLVQ } \\
\hline 1 & Face Detection & Yes & Yes \\
\hline 2 & Eyes Detection & Yes & Yes \\
\hline 3 & $\begin{array}{l}\text { Blink / closed eye } \\
\text { detection }\end{array}$ & No & Yes \\
\hline
\end{tabular}

Cascade because it has capability for detecting face and eye region until recognizing closed and opened state of the eye region, detailed comparison showed in Table 2. Our proposed method also compared with other several previous method that using many approach like horizontal projection [15], pixel value method [16] and contour circle method [17]. Comparison result showed in Table 3.

Referring to Table 3, our proposed method also had more significant accuracy result compared by using pixel value method proposed by Zeeshan et al [16] and Horizontal Projection method proposed by M. Wang et al [15] for recognizing eye closeness state.

Although our proposed method has lower accuracy than the proposed method by $\mathrm{M}$. Wang et al, but our proposed method has several advantages especially it can detect eyes state accurately without being affected by the motion of the eyeball. Methods proposed by M. Wang et al have a problem in the detection process when the position of the eyeball or pupils is not in the middle area.

Contour Circle method by M. Wang et al [17] needs to ensure that pupil eyes area are must be detected and removed. It is become a problem when pupils accidentally are not in a position that easy to detect (middle position) and it can caused pupils cannot be removed correctly and induce unsuitable Contour Circle fitting and caused wrong detection showed in Fig. 13. By using our proposed method, this problem can be solved because our proposed method not affected by eyeball movements and can 
Table 3. Comparison result of proposed method with three others method

\begin{tabular}{|l|c|c|c|c|}
\hline & $\begin{array}{c}\text { Our } \\
\text { Method }\end{array}$ & $\begin{array}{c}\text { Horizontal Projection } \\
\text { by Wen-Chang et al } \\
{[15] .}\end{array}$ & $\begin{array}{c}\text { Pixel Value by Zeeshan } \\
\text { et al [16] }\end{array}$ & $\begin{array}{c}\text { Contour Circle by M. } \\
\text { Wang et al [17] }\end{array}$ \\
\hline Eyes state detection & $90.32 \%$ & $88.5 \%$ & $87 \%$ & $\mathbf{9 6 , 6 \%}$ \\
\hline Computation time & $\mathbf{0 . 0 5} \mathrm{s}$ & $0.17 \mathrm{~s}$ & $0.08 \mathrm{~s}$ & $0.46 \mathrm{~s}$ \\
\hline
\end{tabular}

Table 4. Comparison with contour circle method by M. Wang et al.

\begin{tabular}{|l|l|l|}
\hline & $\begin{array}{l}\text { Our } \\
\text { Proposed } \\
\text { Method }\end{array}$ & $\begin{array}{l}\text { M. Wang et al } \\
{[17]}\end{array}$ \\
\hline $\begin{array}{l}\text { Need to detect pupil / } \\
\text { eyeball }\end{array}$ & NO & Needed \\
\hline $\begin{array}{l}\text { Pupil/eyeball must be } \\
\text { accessible/in the centre }\end{array}$ & NO & Yes \\
\hline $\begin{array}{l}\text { Available to detect } \\
\text { eyes state although } \\
\text { pupil are not looking } \\
\text { forward (looking to the } \\
\text { left or right) }\end{array}$ & YES & No \\
\hline \begin{tabular}{l} 
Computation time \\
\hline
\end{tabular} & $\mathbf{0 . 0 5 ~ s}$ & $0.46 \mathrm{~s}$ \\
\hline
\end{tabular}

recognize the eyes state well although eyeball or eyes pupil are not in the center or not in the place that easy to detect, showed in Fig. 14. Detail of the comparison of the proposed method and Contour Circle method are showed in Table 4.

In another hand, we can assume that HLVQ method are more efficient with time computation are 0.05 second compare to 0.17 seconds using horizontal projection method by Wen-Chang et al, 0.08 seconds using pixel value proposed by Zeeshan et al and 0.46 seconds using contour circle proposed by $\mathrm{M}$. Wang et al. Better time computation result can achieve because our method only works by adding up the pixel value in every column of eye image area and calculating it using the Euclidean distance method inside the LVQ neural network. HLVQ method has simpler step when compared to horizontal projection proposed by Wen-Chang et al

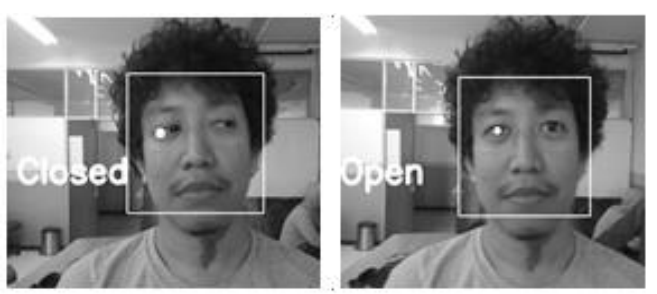

Figure. 13 Blink detection using Contour Circle method. wrong detection caused by pupils are not in the center (left)
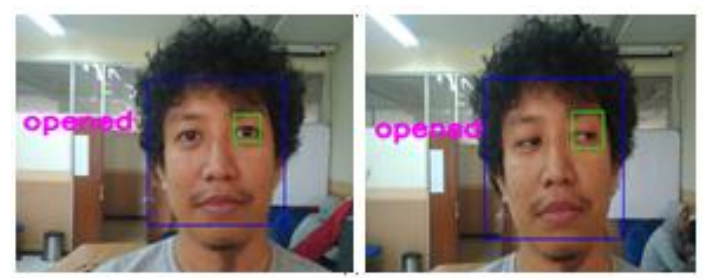

Figure. 14 Blink detection using our proposed method that not affected by pupil position

that include Kalman filter and S-channel image extraction process that caused computation time increased. Our proposed method also has better computation time compared to the pixel value method proposed by Zeeshan et al, it is because pixel value method needs to calculate horizontal projection and vertical projection and then add it up to get pixel value result. Our proposed method also has better computation time compared to the contour circle method proposed by M. Wang et al, it is because the scheme process of Contour Circle method are Face detection - eye detection - pupil detection - remove pupil - fit contour circle recognize, so the total of contour circle method process are 5 steps. Our method also have more shorter process that only need 4 steps for detecting closed eyes, the steps are Face detection - eye detection - VIP process - LVQ neural network eye closeness detection. Those caused that our proposed method has a shorter computation time then contour circle method which has been proposed by M. Wang, that need more steps to recognize include detecting and removing the eyeball first. 


\section{Conclusion}

The Problem about disability became a huge issue now. Many inventor try to develop variation of stuff for help disabled people to do their activities like normal people. By theses problem, we develop a way that combining the Haar cascade method, Vertical Image Projection (VIP) and LVQ neural network called HLVQ for recognizing eye closed state and eye open state for produce a basic command to the system console and connect it to the wheelchair for basic controlling of wheelchair movement. In this research we can prove that HLVQ method have a good capability for recognizing opened and closed state of eyes by locating the eye area in the image and calculate the vertical projection and classified it with LVQ Neural Network. From the testing result we get that HLVQ method produce $90.32 \%$ of accuracy and 0.05 seconds for computation time process. Our method or called HLVQ method had more better significant result if compared with other method such like Horizontal Projection and Kalman Filter [15] and pixel value method [16]. Our proposed method also had ability to detect eye state without being affected by pupils or eyeball position if compared to the contour circle method [17].

Using the results of this study, our method had better computation time and good accuracy that then can be formed a new and more effective way to control the movement of the wheelchair by using eyelids real-time detection for disability user that had a lot of limited for operate their limb.

\section{Future research}

In future, our research should have more capability to recognize better and compute faster than before. The ability of our method should be able to applied in the smart wheelchair for disability user that haven't hand or food for controlling the device. Our method should be an alternate or replacement for tool for controlling wheelchair with more easily operation process by using eyelid movement. The wheelchair also must have capability for direction moving like turn left or turn right by using other schema that easy for disability person.

\section{Acknowledgments}

This research are supported by Computer Vision research group and Computer Science Faculty of Universitas Brawijaya, Indonesia. Authors also grateful for friends and audience who allow their picture to be dataset for our research.

\section{References}

[1] F. Fachrudin, "Penyandang Disabilitas di Indonesia Mencapai 9 Juta Jiwa", okezone, $2015 . \quad$ [Online]. Available: https://news.okezone.com/read/2015/12/03/337 /1260124/penyandang-disabilitas-di-indonesiamencapai-9-juta-jiwa. [Accessed: 02-Jul-2018].

[2] H. S. Jung, G. Park, Y. S. Kim, and H. S. Jung, "Development and evaluation of one-hand drivable manual wheelchair device for hemiplegic patients", Appl. Ergon., Vol. 48, pp. 11-21, 2015.

[3] L. A. Rivera and G. N. Desouza, "A power wheelchair controlled using hand gestures, a single sEMG sensor, and guided underdetermined source signal separation", In: Proc. of IEEE RAS EMBS Int. Conf. Biomed. Robot. Biomechatronics, pp. 1535-1540, 2012.

[4] D. Wang and H. Yu, "Development of the control system of a voice-operated wheelchair with multi-posture characteristics", In: Proc. of 2017 2nd Asia-Pacific Conf. Intell. Robot Syst. ACIRS 2017, pp. 151-155, 2017.

[5] N. Peixoto, H. G. Nik, and H. Charkhkar, "Voice controlled wheelchairs: Fine control by humming", Comput. Methods Programs Biomed., Vol. 112, No. 1, pp. 156-165, 2013.

[6] R. Hardiansyah, "The Electric Wheelchair Control Using Electromyography Sensor Of Arm Muscle", In: Proc. of 2016 International Conference on Information \& Communication Technology and Systems (ICTS), pp. 129-134, 2016.

[7] F. Utaminingrum, M. A. Fauzi, R. C. Wihandika, S. Adinugroho, T. A. Kurniawan, D. Syauqy, Y. A. Sari, and P. P. Adikara, "Development of computer vision based obstacle detection and human tracking on smart wheelchair for disabled patient", In: Proc. of the 5th Int. Symp. Comput. Bus. Intell. ISCBI 2017, pp. 1-5, 2017.

[8] S. Plesnick, D. Repice, and P. Loughnane, "Eye-controlled wheelchair", In: Proc. of 2014 IEEE Canada Int. Humanit. Technol. Conf. IHTC 2014, 2014.

[9] R. P. Prasetya and F. Utaminingrum, "Triangle similarity approach for detecting eyeball movement", In: Proc. of the 5th Int. Symp. Comput. Bus. Intell. ISCBI 2017, pp. 37-40, 2017.

[10] R. P. Prasetya, F. Utaminingrum, and W. F. Mahmudy, "Real time eyeball movement detection based on region division and midpoint position", International Journal of 
Intelligent Engineering and Systems, Vol. 11, No. 3, pp. 149-158, 2018.

[11] L. Ke and J. Kang, "Eye location method based on Haar features", In: Proc. of 2010 3rd Int. Congr. Image Signal Process. CISP 2010, vol. 2, pp. 925-929, 2010.

[12] M. S. Uddin and A. Y. Akhi, "Horse Detection Using Haar Like Features", Int. J. Comput. Theory Eng., Vol. 8, No. 5, pp. 415-418, 2016.

[13] A. Kadir and A. Susanto, Teori dan Aplikasi Pengolahan Citra. Yogyakarta: Penerbit Andi, 2013.

[14] S. Kusumadewi, Artificial Inteligence (Teknik dan Pengaplikasiannya). Yogyakarta: Graha Ilmu, 2003.

[15] W. Cheng, H. Liao, M. Pan, and C. Chen, "A Fatigue Detection System with Eyeglasses Removal", In: Proc. of 2013 15th International Conference on Advanced Communications Technology (ICACT), pp. 331-335, 2013.

[16] Z. A. Haq and Z. Hasan, "Eye-blink rate detection for fatigue determination", In: Proc. of India Int. Conf. Inf. Process. IICIP 2016 Proc., 2017.

[17] M. Wang, L. Guo, and W. Y. Chen, "Blink detection using Adaboost and contour circle for fatigue recognition", Comput. Electr. Eng., Vol. 58, pp. 502-512, 2017. 